\title{
Novel hormone-regulated genes in visceral adipose tissue: cloning and identification of proinflammatory cytokine-like mouse and human MEDA-7: implications for obesity, insulin resistance and the metabolic syndrome
}

\author{
H. Zhang $\cdot$ X. Chen $\cdot$ M. R. Sairam
}

Received: 31 March 2011 / Accepted: 9 May 2011 / Published online: 19 June 2011

(C) Springer-Verlag 2011

\begin{abstract}
Aims/hypothesis We sought to characterise novel genes dysregulated by sex hormonal imbalances that induce obesity and metabolic disorder in a setting of oestrogen deficiency and androgen dominance in follicle-stimulating hormone receptor (For [also known as $F s h r]$ ) knockout female mice.

Methods Transcriptome analysis of mesenteric adipose tissue (MAT) of mutants revealed novel genes. One novel gene named Meda-7 was selected for study. Meda-7 was cloned from mouse and human adipose tissue; its expression, hormonal regulation and function were characterised.

Results Mouse Meda-7 is richly expressed in deep visceral adipose tissue and encodes a $22 \mathrm{kDa}$ secreted protein with
\end{abstract}

M.R. Sairam dedicates this article to the memory of his mentor Emeritus Professor Dr N.R. Moudgal.

Electronic supplementary material The online version of this article (doi:10.1007/s00125-011-2212-7) contains peer-reviewed but unedited supplementary material, which is available to authorised users.

H. Zhang $\cdot$ X. Chen $\cdot$ M. R. Sairam $(\bowtie)$

Molecular Endocrinology Laboratory,

Clinical Research Institute of Montreal,

110 Pine Avenue West,

Montréal, QC, Canada H2W 1R7

e-mail: sairamm@ircm.qc.ca

\section{R. Sairam}

Département de Médecine, Université de Montréal,

Montréal, QC, Canada

\section{R. Sairam}

Department of Medicine, Division of Experimental Medicine,

McGill University,

Montréal, QC, Canada

\section{R. Sairam}

Department of Physiology, McGill University,

Montréal, QC, Canada
$71 \%$ homology to human mesenteric oestrogen-dependent adipose gene- 7 (MEDA-7) protein. Both have six conserved cysteines like many cytokines. In obese patients, MEDA-7 is more abundant in omental than subcutaneous fat. Meda-7 is downregulated in For-knockout female MAT at 5 months (obese state) followed by steep upregulation at 9 months (prediabetic condition) when mutants progress towards the metabolic syndrome. Meda-7 is expressed predominantly in the stromal-vascular cell fraction. In this fraction, M1-proinflammatory macrophages are rich in Meda-7. Meda-7 dysregulation in 5-month-old For-knockout MAT is restored by oestrogen, but treatment has no effect in older mutants. Overabundance of MEDA-7 in HEK-293 cells enhances cell proliferation via p42/44 mitogen-activated protein kinases. Secreted MEDA-7 attenuates insulin-stimulated glucose uptake in 3T3-L1 adipocytes, while downregulating glucose transporter-4 and upregulating both monocyte chemotactic protein-1 and suppressor of cytokine signalling-3. Downstream activity of the insulin signalling mediator, phospho-AKT, is also downregulated. Conclusions/interpretation MEDA-7 is a hormone-regulated adipokine/proinflammatory cytokine that is implicated in causing chronic inflammation, affecting cellular expansion and blunting insulin response in adipocytes.

Keywords Adipocyte - Insulin response - Macrophage · MEDA-7 - Oestrogen effect - Proinflammatory cytokine . Proliferation - Visceral obesity

$\begin{array}{ll}\text { Abbreviations } \\ \text { CCL } & \text { Chemokine (C-C motif) ligand } \\ \text { EST } & \text { Expressed sequence tag } \\ \text { FSH } & \text { Follicle-stimulating hormone } \\ \text { GFP } & \text { Green fluorescent protein } \\ \text { HFD } & \text { High-fat diet }\end{array}$

Abbreviations

CCL Chemokine (C-C motif) ligand

EST Expressed sequence tag

FSH Follicle-stimulating hormone

HFD High-fat diet 


$\begin{array}{ll}\text { LPS } & \text { Lipopolysaccharide } \\ \text { MAPK } & \text { Mitogen-activated protein kinase } \\ \text { MAT } & \text { Mesenteric adipose tissue } \\ \text { MCP } & \text { Monocyte chemotactic protein } \\ \text { MEDA-7 } & \text { Mesenteric oestrogen-dependent adipose gene 7 } \\ \text { MTT } & \begin{array}{l}\text { 3-(4,5-Dimethylthiazol-2-yl)-2,5- } \\ \text { diphenyltetrazolium bromide }\end{array} \\ \text { ORF } & \text { Open reading frame } \\ \text { PACAP } & \begin{array}{l}\text { Proapoptotic caspase-2- and caspase-9-binding } \\ \text { protein }\end{array} \\ \text { PAT } & \text { Perigonadal adipose tissue } \\ \text { SAT } & \text { Subcutaneous adipose tissue } \\ \text { SVC } & \text { Stromal vascular cell } \\ \text { VAT } & \text { Visceral adipose tissue } \\ \text { WAT } & \text { White adipose tissue }\end{array}$

\section{Introduction}

Visceral obesity as a major risk factor for the metabolic syndrome is increased in postmenopausal women [1] and in sex hormone imbalance endocrine disorders such as hyperandrogenaemia in polycystic ovary syndrome [2]. These women have a higher risk of cardiovascular disease and type 2 diabetes [3-5]. Oestrogen replacement therapy decreases abdominal fat [6] and increases bone density [7] in postmenopausal women. However, benefits of oestrogen replacement vs risk of progression of coronary artery atherosclerosis and diabetes are contentious [5, 8, 9]. Therefore, understanding mechanistic issues of links between visceral obesity and the metabolic syndrome would help devise interventions and derive site-specific as well as age-related benefits in menopausal women.

White adipose tissue (WAT) consists of several depots such as abdominal visceral adipose tissue (VAT) and subcutaneous adipose tissue (SAT). VAT is distinguished from SAT by its anatomy and distinct secretion patterns of adipocytokines [10,11]. Abdominal deep VAT, including mesenteric adipose tissue (MAT) in mice and omental fat in humans, exerts a more direct influence on liver metabolism. These secretions, collected by the portal vein, reach the liver at much higher concentrations than other visceral depots such as perigonadal and perirenal fat depots, whose veins drain into systemic circulation [11, 12]. Deep VAT is a major site of the chronic low-grade inflammation associated with obesity and also a sensitive insulin resistance predictor $[13,14]$. Adipose tissue stromal vascular cells (SVC) in obese persons express increasing amounts of proinflammatory molecules such as Tnf $\alpha, \mathrm{Il}-6$ and monocyte chemotactic protein (MCP)-1 [15]. Proinflammatory adipose tissue macrophages serve as a link between obesity and insulin resistance [16]. As an endocrine organ, adipose tissue and the adipokines and cytokines derived from it play important roles in energy homeostasis, inflammation and insulin resistance [17]. In addition to known genes, $40 \%$ of genes expressed in adipose tissue are novel and $20-30 \%$ of these may encode secreted proteins requiring biochemical and physiological characterisation [18].

Follicle-stimulating hormone (FSH) receptor disruption produces chronic oestrogen deficiency and hyperandrogenaemia in female mice $[19,20]$. In FSH receptor (For [also known as Fshr]) knockout mice, we previously drew attention to early obesity induced by hormonal imbalances: a low oestrogen:androgen ratio was associated with visceral obesity and onset of glucose intolerance, fatty liver and dyslipidaemia [21, 22]. This model allowed us to distinguish between deep VATs such as those surrounding mesenteric vessels and perigonadal adipose tissue (PAT) [22] and suggest that anatomical location causes distinct biological effects.

This led us to hypothesise that comparing abdominal adipose depots could reveal differences in the nature and/or quantity of these depots, and sex-dependent effectors. In the present work, we used For-knockout female mice to discover novel hormone-regulated, deep VAT-specific genes that are dysregulated and functionally involved in linking sex hormonal imbalances with obesity and insulin resistance. We show that a novel adipokine/proinflammatory cytokine, MEDA-7 (MEDA in Sanskrit to mean fat and standing for mesenteric oestrogen-dependent adipose gene 7 [Meda-7]), is hormonally regulated and implicated in contributing to chronic inflammation, cellular expansion and insulin resistance.

\section{Methods}

Animals and human tissue collection

Animals The animal care committee approved our study. For-knockout mice were established and housed as described $[21,22]$. To test the effects of a high-fat diet (HFD), mice were fed a diet with $45 \%$ energy as fat from lard and soyabean oil [22].

Human participants Paired biopsies of SAT and omental fat were collected from obese patients during laparoscopic surgery. Investigations were approved by the hospital ethics committee and participants gave written informed consent.

\section{Affymetrix gene microarray}

RNA from MAT of 5-month-old wild-type or For-knockout mice was used. Analyses (Affymetrix $39 \mathrm{~K}$ GeneChip Mouse Genome 4302.0 Array; Affymetrix, Santa Clara, 
CA, USA) were done using equipment and protocols from the supplier. Data analysis was performed using GeneSpring software (Agilent Technologies, Mississauga, ON, Canada) with default normalisation [23].

\section{RT-PCR, PCR and quantitative PCR}

Expression of several genes in Figs 2 and 4 was determined by RT-PCR in relation to GAPDH. The sequences of specific PCR primers for RT-PCR and quantitative PCR are in the electronic supplementary material (ESM) Table. RT-PCR variables are described in ESM Method-1. Quantitative PCR was performed as described [22].

Isolation of full-length cDNA clones from mouse adipose tissue

Because expressed sequence tag (EST) of Meda-7 is derived from the 3' end, an RNA ligase-mediated RACE system (FirstChoice; Ambion, Austin, TX, USA) was used to generate 5'-RACE PCR templates. PCR products were cloned into P driver vector (Qiagen, Mississauga, ON, Canada) and transformed into Escherichia coli. Isolated plasmid DNA was sequenced for assembly using Sequencer 4.7 software (Gene Codes Corporation, Ann Arbor, MI, USA).

Cloning and recombinant expression of mouse and human $M E D A-7$ open reading frame

Both $M E D A-7$ open reading frames (ORFs) were cloned into vector pIRES2 with green fluorescent protein (GFP) and V5 tag. GFP not fused to inserted protein allows monitoring of transfection efficiency. HEK-293 cells were transfected with MEDA-7 ORF plasmid DNA using Lipofectamine 2000 (Invitrogen, Burlington, ON, Canada). After $48 \mathrm{~h}, \mathrm{G} 418(600 \mu \mathrm{g} / \mathrm{ml})$ was added for selection. After 2 weeks, HEK-293 mouse or human MEDA-7 ORF stable cell lines were established and expression confirmed by western blot. A stable clone of ovarian cancer UCI-107 cells expressing human MEDA-7 ORF was also produced.

Western blotting and protein localisation

For western blot, proteins in cell lysate and supernatant fractions $(50 \mu \mathrm{g})$ were separated by SDS-PAGE and transferred to polyvinylidene difluoride membranes [22]. MEDA-7 antibody was preincubated with synthetic peptide $(3 \mu \mathrm{g} / \mathrm{ml})$ to determine specificity. $\beta$-Actin was used as a housekeeping gene. Protein localisation was determined by immunofluorescence (for details see ESM Method-2).
Isolation of SVC and adipocyte fraction, and macrophage sorting

The SVC and adipocyte fraction were obtained from PAT of 5 -month-old wild-type female mice as described [15]. For cell sorting, pelleted erythrocyte-depleted SVCs from the wild-type PAT pool were resuspended in FACS buffer (PBS $+0.2 \%$ [wt/vol.] fatty acid-poor BSA). Isolated cells were incubated with F4/80-APC and CD11C-FITC (eBioscience, San Diego, CA, USA ) to sort macrophages into M1 (F4/ $\left.80^{+} \mathrm{CD} 11 \mathrm{c}^{+}\right)$and $\mathrm{M} 2\left(\mathrm{~F} 4 / 80^{+} \mathrm{CD} 11 \mathrm{c}^{-}\right)$phenotype [24], and processed for RNA.

Peritoneal macrophages

Thioglycolate-elicited peritoneal macrophages were collected from 3-month-old wild-type mice [25]. PBS-washed cells resuspended in RPMI 1640 supplemented with $10 \%$ FBS were plated $\left(10^{6}\right.$ cells/well). Non-adherent cells were removed after $2 \mathrm{~h}$ and medium was replaced. RNA was isolated from cells grown for $16 \mathrm{~h}$ in medium with or without lipopolysaccharide (LPS) $100 \mathrm{ng} / \mathrm{ml}$.

\section{Oestrogen replacement}

Mice were treated with oestradiol-17 $\beta$ ( $1 \mu \mathrm{g} /$ day for 10 days) [19] and MAT was processed for RNA.

\section{Cell proliferation}

HEK-293 cells were grown at $37^{\circ} \mathrm{C}$ under $5 \% \mathrm{CO}_{2}$ in DMEM $+10 \%$ heat-inactivated serum. We analysed five variables: (1) cell proliferation by 3-(4,5-dimethylthiazol-2yl)-2,5-diphenyltetrazolium bromide (MTT) assay (Invitrogen); (2) cell counting; (3) cell cycle: $1 \times 10^{6}$ cells were fixed in $70 \%$ ethanol for $30 \mathrm{~min}$ at $4^{\circ} \mathrm{C}$, then washed and resuspended in $1 \mathrm{ml}$ PBS with $50 \mu \mathrm{g} / \mathrm{ml}$ propidium iodide and $20 \mu \mathrm{g} / \mathrm{ml}$ RNAse A (Sigma-Aldrich, Oakville, ON, Canada), followed by FACS analysis (Becton Dickenson, Oxford, UK) using MODFIT LT software (Verity Software House, Topsham, ME, USA), resulting in 10,000 single events being recorded each time and percentage of cells in G1, G2 and S phases being calculated; (4) soft agar assay for colony formation by human MEDA-7 ORF stably transfected HEK-293 cells and UCI-107 cells; and (5) western blot assessment of mitogen-activated protein kinase (MAPK) activity involved in cell proliferation.

Glucose uptake in adipocytes

Insulin-stimulated glucose uptake was measured [26] using differentiated 3T3-L1 cells. On day 7, recombinant 
MEDA-7 (2 and $5 \mathrm{nmol} / \mathrm{l}$ ) was added to cells for $20 \mathrm{~h}$, followed by serum-free MEDA-7 or control media for an additional $4 \mathrm{~h}$. Cells were treated for $20 \mathrm{~min}$ with or without $200 \mathrm{nmol} / 1$ insulin at $37^{\circ} \mathrm{C}$ and processed for glucose uptake, RNA and protein analysis. Membrane fractions were prepared according to published procedures [27] (see ESM Method-3 for details). Glucose uptake was initiated by 2-deoxy-D $\left[1,2-{ }^{3} \mathrm{H}\right]$ glucose addition (PerkinElmer, Woodbridge, ON, Canada) $\left(37 \mathrm{kBq}\right.$ for $10 \mathrm{~min}$ at $\left.37^{\circ} \mathrm{C}\right)$. Radioactivity in cell lysate was then determined. The method used to determine the concentration of recombinant MEDA-7 was based on a competitive ELISA assay using polyclonal antibodies against mouse MEDA-7 peptide (ESM Method-4).

\section{Statistics}

Results were analysed using SigmaStat3.1 (SYSTAT, Point Richmond, CA, USA). Values are presented as mean $\pm \mathrm{SEM}$. The $t$ test was used when comparing only one factor between two groups. Otherwise, we used ANOVA followed by Bonferroni's $t$ test as specified. Statistical differences were considered significant at $p<0.05$.

\section{Results}

MAT transcriptome and discovery of novel gene Meda-7

To identify novel genes linking early visceral obesity and late onset of the metabolic syndrome in For-knockout females [21, 22], we compared MAT transcriptome in 5month-old For-knockout and wild-type littermates. This identified 2186 dysregulated ( $\geq$ twofold) transcripts. Using the DAVID Gene Functional Classification Tool (http:// david.abcc.ncifcrf.gov), genes were clustered into functional groups (Fig. 1a). We focused exclusively on unknown genes, applying strict criteria to select genes for further study. First, using bio-informatics to deduce predicted hypothetical protein ORFs, we attributed significance if the gene was also predicted in humans. Second, we stipulated adipose tissue expression and disease association, as found in For-knockout. Third, we chose predicted proteins with features for functional analysis. Thus one EST identified by probe ID '1428947_at' was severely downregulated in For-knockout MAT to 8\%. BLAST search (http://blast.ncbi.nlm.nih.gov/Blast.cgi) matched with an uncharacterised transcript: Mus musculus RIKEN cDNA 2010001M09 gene. We named this Meda-7. Its alteration in For-knockout adipose tissue was confirmed by quantitative PCR. Thus Meda-7 expression decreased to $8 \%$ at 5 months in For-knockout MAT (Fig. 1b) consistent with microarray data and tended to decrease in For-knockout PAT (Fig. 1c). However, by 9 months, when mutants become prediabetic
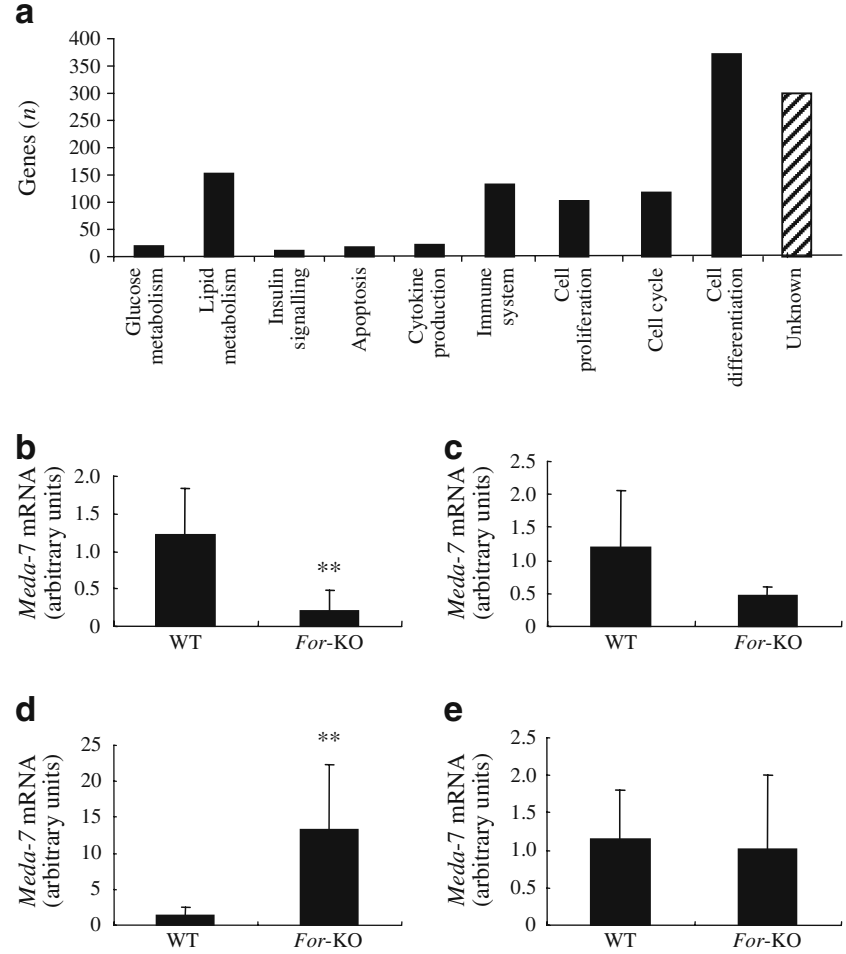

Fig. 1 Functional classification of dysregulated genes in Forknockout MAT. Transcriptome of adipose tissue from 5-month-old wild-type (WT) and For-knockout (For-KO) mice $(n=3)$ was compared by Affymetrix microarray. a Dysregulated genes ( $\geq$ twofold difference) were clustered into different functional groups, with 299 genes, including Meda-7, remaining uncharacterised. Meda-7 expression by quantitative PCR at 5 months in wild-type and For-knockout mice in (b) MAT $\left({ }^{* *} p<0.01, n=8\right)$ and (c) PAT. Meda-7 expression at 9 months in WTand For-KO (prediabetic state) in (d) MAT $(* * p<0.01, n=8)$ and (e) PAT

[22], Meda-7 was upregulated 8.6-fold in MAT (Fig. 1d) but not in PAT (Fig. 1e). Thus Meda-7 was dysregulated in For-knockout females selectively in VAT in an age- and disease-related manner.

Cloning of mouse and human MEDA-7 and MEDA-7 protein characteristics

The mouse microarray probe matched to the $3^{\prime}$ end of a predicted cDNA (NM_027222.2). We performed 5' RACE to extend the $5^{\prime}$ region and assembled the full sequence. Sequence of adipose tissue mouse Meda-7 cDNA showed four nucleotides to be different at positions 74, 130, 441 and 761. Three changes produce in-frame mismatches with predicted ORF: TTC (Phe) vs TTA (Leu), CCC (Pro) vs CAC (His) and AAT (Asn) vs AGT (Ser). These were confirmed in two other strains (C57/BL6 and Swiss Webster) prone to diet-induced obesity [28]. Mouse Meda-7 gene mapping to chromosome $18 \mathrm{~B} 2$ has four exons and three introns spanning 2,096 bp (ESM Fig. 1a). 
Mouse Meda-7 ORF codes for a protein of 188 amino acids.

We then cloned human adipose tissue MEDA-7 ORF using primers at both ends. Sequencing confirmed $100 \%$ match to hypothetical protein LOC51237. Human MEDA-7 gene mapping to chromosome $5 \mathrm{q} 31$ (ESM Fig. 1b) is located near a cluster of known cytokine genes such as IL3, IL5, IL4, IL13, IL9 and CXCL14. Human MEDA-7 cDNA codes for a 189 amino acid hypothetical protein MGC29506 (accession number NP_057543). Human MEDA-7 shows high homology with other species (ESM Fig. 1c and $\mathrm{d}$ for accession number). Six cysteines are conserved in all species, a characteristic of many cytokines that form three disulfide bonds, including IL-17, MCP-3, chemokine (C-C motif) ligand (CCL)15, CCL21 and CCL23 [29-31]. Mouse and human MEDA-7 contain an $\mathrm{N}$-terminal signal peptide $1-22$, which can yield a secreted protein (166 for mouse and 167 amino acids for human) (ESM Fig. 1e and f). Prediction tool CTKPred [32] suggested that mouse and human MEDA-7 belong to the cytokine family.

The 'Eukaryotic Linear Motif' resource predicts several functional sites in human MEDA-7 protein, including major TNF receptor-associated factor 2-binding motif [33, 34], signal transducer and activator of transcription (STAT) 5 Src-homology-2 domain binding [35, 36] and immunoreceptor tyrosine-based inhibitory motif [37], suggesting potential involvement in insulin signalling and inflammatory regulation.

\section{Adipose tissue MEDA-7 dynamics}

In addition to high expression in MAT, Meda-7 is also expressed in metabolic and reproductive organs of 3- to 5month-old wild-type females, such as pancreas and kidney, followed by intermediate levels in PAT, uterus, SAT, heart, muscle, ovary and liver, and very low expression in brown adipose tissue (Fig. 2a). Analysis of Meda-7 expression in PAT in mice (Fig. 2b) showed that Meda-7 mRNA levels were significantly higher in SVCs that in adipocytes. Adiponectin (Fig. 2c) and Tnfo (Fig. 2d) expression was examined as markers of two fractions. Macrophages, as an important component of SVCs, contribute to chronic inflammation in obesity. Meda-7 was expressed in mouse macrophage RAW 264.7 cell line, and $F 4 / 80$ and Tnf $\alpha$ were both detectable in these cells (Fig. 2e).

As paracrine macrophage-adipocyte cross-talk drives local and systemic insulin resistance [15, 17], we examined SVCs by FACS analysis. The macrophage $\left(\mathrm{F} 4 / 80^{+}\right.$cells $)$ component in For-knockout SVCs increased to $37 \%$ vs $15 \%$ in wild-type SVCs at 9 months, supporting macrophage involvement in the prediabetic state in For-knockout mice at this age. Macrophages are subgrouped into proinflammatory M1 and non-inflammatory regulatory M2 phenotypes [38]. We sorted M1 phenotype (F4/80 $0^{+}$, CD $11 \mathrm{c}^{+}$

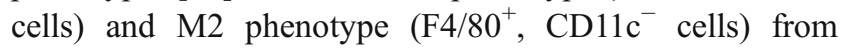
SVCs of 9-month-old wild-type female PAT (Fig. 2f) and found Meda-7 expression in both fractions, but consistently higher in the M1 fraction (Fig. 2g). The pattern for other M1-associated cytokines, e.g. Il-6 and Mcp-1, was similar. Challenge with LPS, an endotoxin and Toll-like receptor-4 ligand, promotes secretion of proinflammatory macrophage cytokines [39]. LPS-stimulated peritoneal macrophages increased endogenous Meda-7 mRNA (Fig. 2h) confirming its proinflammatory phenotype; control proinflammatory $M c p-1$ was also upregulated. Immunofluorescence using MEDA-7 peptide antibody localised this protein in the cytoplasm of adipose tissue SVC fraction (Fig. 2i). A protein band of $22 \mathrm{kDa}$ from SVC lysate by western blotting matched the predicted size (Fig. 2j); this was blocked by MEDA-7 synthetic peptide antibody.

We next examined Meda-7 in different adipose tissue depots as well as by sex and age. Expression was higher in WAT, including MAT, PAT and SAT (Fig. 2k), suggesting a primary function in energy-storing WAT as opposed to thermogenic brown adipose tissue. Meda-7 in MAT differed between male and female mice (ESM Fig. 2a). In wild-type mice, Meda-7 was 10 times higher in females than males, but there was no sex-related difference in For-knockout MAT. Examining Meda-7 in MAT with ageing in females, we found a decrease in wild-type MAT. However, in Forknockout females, there was a clear trend for Meda-7 expression to increase with ageing (ESM Fig. 2b). Meda-7 expression was influenced by chronic HFD (Fig. 21), increasing $125 \times$ in wild-type and $75 \times$ in For-knockout MAT on HFD compared with regular diet at 9 months.

\section{MEDA-7 is a secreted protein}

By western blotting, MEDA-7 protein was found in cell lysate and culture medium of HEK-293 Meda-7 ORF cells (molecular mass $22 \mathrm{kDa}$ ) (ESM Fig. 2c) confirming theoretical prediction of MEDA-7 as a secreted protein. The protein band intensity in the culture medium indicated efficient secretion. Signal peptide (residues 1-22) deletion prevented secretion and the corresponding truncated protein was detectable only in cell lysate (not shown). Truncated MEDA-7 is diffuse in the cytoplasm (ESM Fig. 2d).

MEDA-7 regulation by oestrogen

Since we initially discovered MEDA-7 in MAT following dysregulation during sex hormonal imbalance, we verified oestrogen's influence on gene expression. Treatment of 5month-old For-knockout mice with oestradiol-17 $\beta$ had remarkable effects. Among the reproductive organs, the uterus 


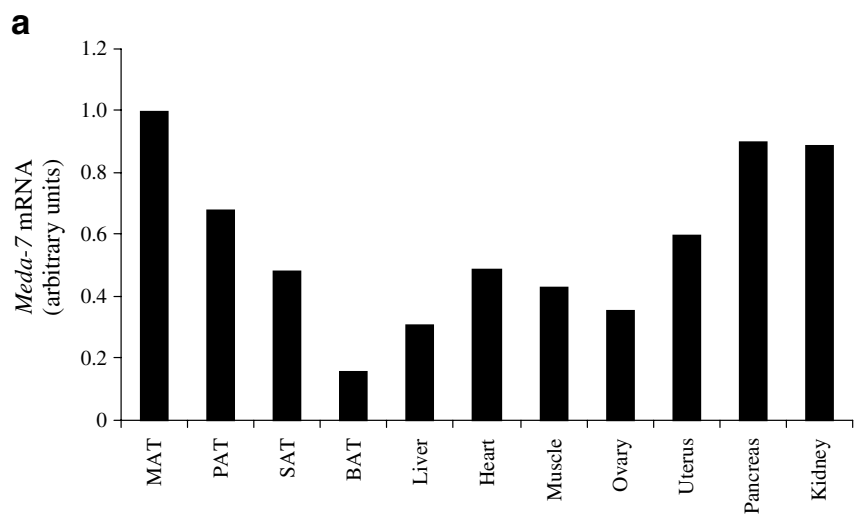

b

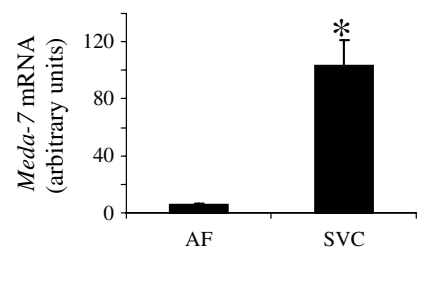

C

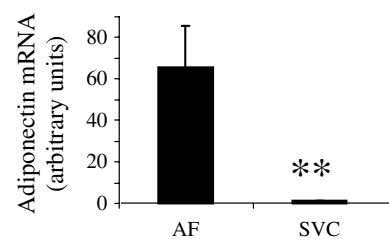

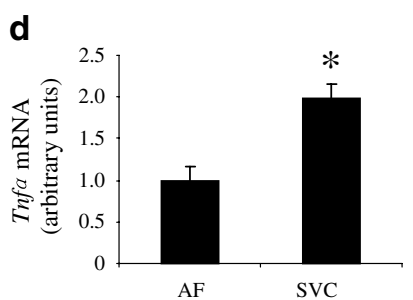

。

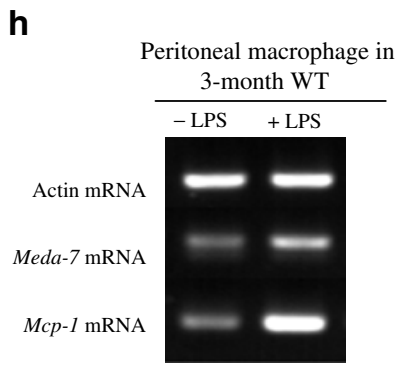

i
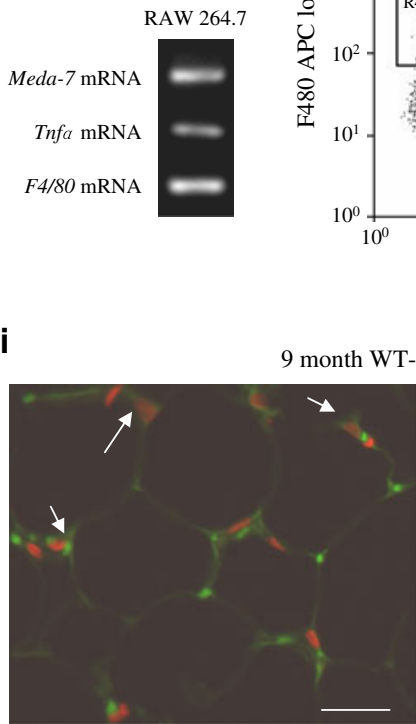

MEDA-7

f

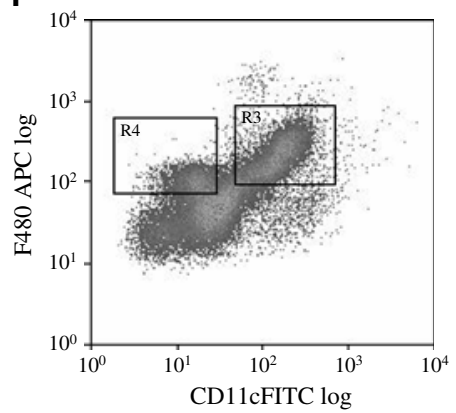

Normal rabbit ser

g

SVC macrophage in 9-month WT

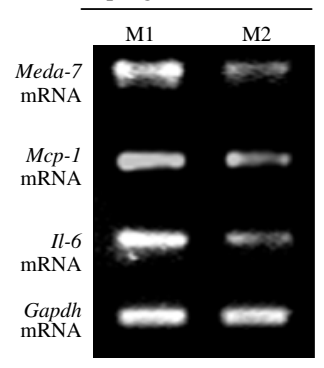

j
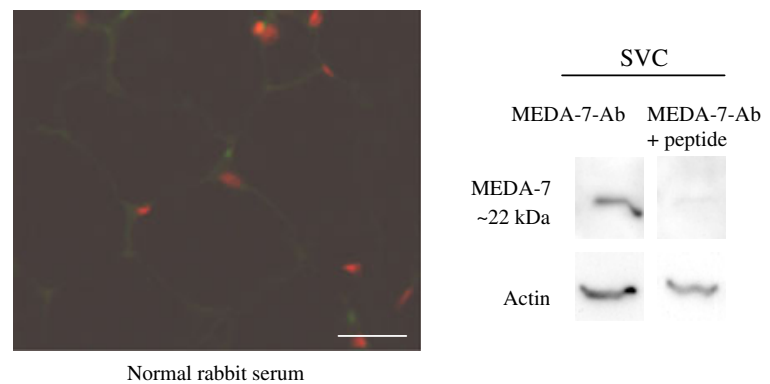

k

I
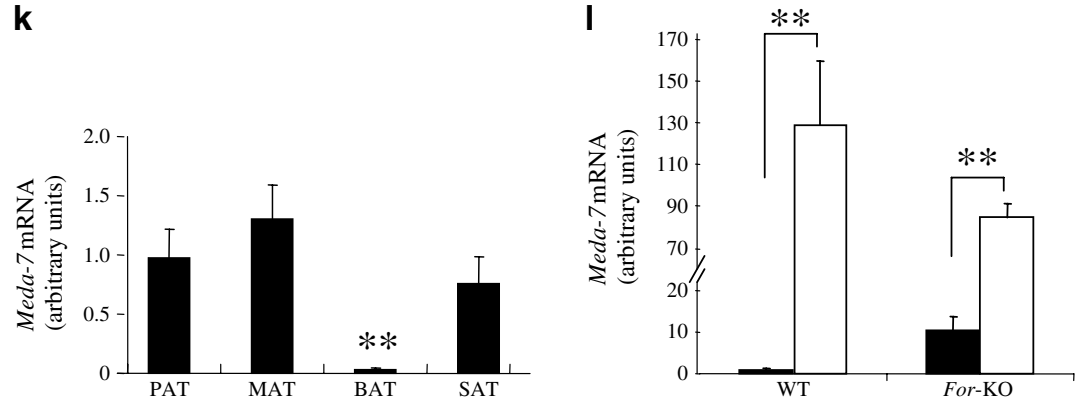

For-knockout + placebo group (Fig. 3). Oestrogen had no effect on the expression of Meda-7 in PAT (not shown), indicating that regulation at this age is restricted to selective abdominal fat depots. Oestrogen did not influence Meda-7 expression in fat depots of For-knockout mutants at 11 months (not shown). 
4Fig. 2 Tissue expression of Meda-7 in mouse. a Meda-7 expression in different metabolic and selected reproductive organs was determined by quantitative PCR using specific primers and normalised to Gapdh. Wild-type (WT) female mice at 3-5 months of age $(n=3)$ were used for this comparison. BAT, brown adipose tissue. b Compartmental expression of Meda-7 in 9-month-old wild-type PAT in SVC vs adipocyte fraction (AF) by quantitative PCR, with (c) adiponectin and (d) Tnf $\alpha$ expression examined as markers of two fractions to confirm effective separation. e Meda-7 expression in RAW 264.7 by PCR. F4/80 and Tnf $\alpha$ mRNA were also detectable in the same samples. f Macrophages were sorted from SVC derived from PAT of 9-monthold wild-type mice. g Expression of Meda-7 and two known proinflammation genes, $M c p-1$ and $I l-6$, in the fractions $\mathrm{M} 1: \mathrm{F} 4 / 80^{+}$and $\mathrm{CD}_{11 \mathrm{c}^{+}}$(R3) and M2: F4/80 ${ }^{+}$and $\mathrm{CD} 11 \mathrm{c}^{-}$cells (R4). h Peritoneal macrophages were cultured overnight with and without LPS (100 ng/ml). Meda-7 mRNA in macrophage was increased after LPS stimulation. Proinflammatory gene $M c p-1$ was also expressed and increased after LPS stimulation. i Immunofluorescence staining of MEDA-7 (white arrows) in PAT from 9-month-old wild-type mice. MEDA-7-producing cells in green were detected by MEDA-7 antibody and localised in SVC. Within the cell, the staining was localised in cytoplasm. Propidium iodide staining (red) indicates cell nucleus. Pre-immune normal rabbit serum was used as negative control. Scale bars $30 \mu \mathrm{m}$. j Western blotting of MEDA-7 in adipose tissue. Cell lysate of SVC from PAT of 9-month-old wild-type mice were processed using MEDA-7 antibody (Ab) $(1.5 \mu \mathrm{g} / \mathrm{ml}$; GenScript, Piscataway, NJ, USA). The $22 \mathrm{kDa}$ band disappears after antibody incubation with peptide antigen. Anti-actin (1:6,000; Santa Cruz, Santa Cruz, CA, USA) was used as control for loading. k Different expression levels of Meda-7 in different mouse fat depots. Four fat depots from 5-month-old wild-type female mice were compared by quantitative PCR. Meda-7 expression was higher in white adipose tissue including PAT, MAT and SAT than in BAT; $n=4 .{ }^{* *} p<0.01$ by one-way ANOVA, $F=7.245$. I Effect of chronic HFD (white) on adipose tissue Meda-7 expression in wild-type (WT) and Forknockout (For-KO) females by quantitative PCR analysis. At 9 months, HFD strongly influenced Meda-7 expression (125-fold in wild-type, 75-fold in For-knockout MAT under HFD compared with regular diet [black]; $n=6$ ). ${ }^{* *} p<0.01$ by two-way ANOVA, $F=24.07$. When comparing wild-type on regular diet with For-knockout on regular diet, there were significant increases in the latter; $n=6 ; p<0.05$

\section{Characterisation of human adipose tissue MEDA-7}

MEDA-7 was expressed in omental fat and SAT from obese patients (three women, one man), but levels in the former

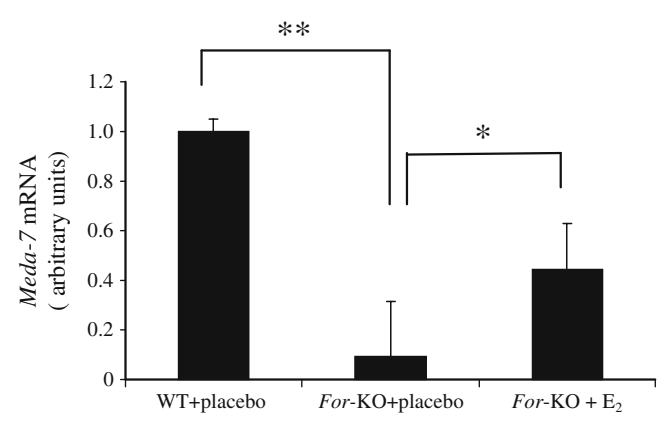

Fig. 3 Oestrogen regulation of Meda-7 expression in adipose tissue. Female mice (5-month- old) were treated with oestradiol-17 $\beta\left(E_{2}\right)$ for 10 days. MAT was processed for RNA and expression determined by PCR; $n=5, * p<0.05,{ }^{* *} p<0.01$ were three times higher (Fig. 4a). Previously an isoform of human MEDA-7 (called proapoptotic caspase-2- and caspase-9-binding protein [PACAP]) had been cloned and characterised as a proapoptotic adaptor protein with 123 residues [40]. However, when our adipose tissue studies began, neither human nor mouse MEDA-7 had been characterised. Due to a frame shift, the coding sequence is altered producing a transcript in which the first $59 \mathrm{~N}$ terminal residues are identical and diverge thereafter [40, 41] (ESM Fig. 3). To differentiate these transcripts, we designed primers specific for $M E D A-7$ or $P A C A P$ (ESM Table). $M E D A-7$ was the predominant isoform in adipose tissue compared with $P A C A P$. As a positive control for the primers, expression of $P A C A P$ and $M E D A-7$ was found in Jurkat cells (Fig. 4b).

Transfection of human MEDA-7 ORF in HEK-293 cells and western blotting (Fig. 4c) showed a single $22 \mathrm{kDa}$ band in cell lysate and medium. Proteomic analysis confirmed structural composition of the secreted band in medium (data not shown).

\section{MEDA-7 increases cell proliferation}

In view of a previous report that the PACAP isoform induced apoptosis [40], we were intrigued by survival of HEK-293 cells used for transfection and protein confirmation for mouse and human MEDA-7. Stable cells showed higher growth rate than cells with vector DNA (Fig. 5a). Proliferation was confirmed by MTT assay (1.8×) (Fig. 5b). Cell cycle analysis showed a significant increase of diploid synthesis in HEK-293-MEDA-7 cells (Table 1). MEDA-7 had no effect on cell death. In addition, anchor-independent growth assay showed increasing colony formation after 2 weeks in HEK-293-MEDA-7 cells (1.4×) (Fig. 5c). Evaluating additional cell types, we found that human MEDA-7 in UCI-107, a human ovarian cancer cell line, significantly increased the number $(1.5 \times)$ and size of colonies (Fig. 5d and e). Further probing MEDA-7 effects on proliferation, we evaluated MAPK as a potential intracellular signalling pathway. Robust activation of $\mathrm{p} 44 /$ 42 MAPK was evident in cytosolic extracts of HEK-293$M E D A-7$ stable clone (2.6×) (Fig. 5f and g). Therefore, MEDA-7 was able to mediate cell proliferation via $\mathrm{p} 44 / 42$ MAPK signalling.

Effect of MEDA-7 on insulin-dependent glucose uptake in adipocytes

We evaluated the effect of MEDA-7 on adipocyte insulin sensitivity by using differentiated 3T3-L1 adipocytes and verifying insulin-dependent glucose transport. Preadipocyte factor-1 (Fig. 6a) and adipocyte fatty acid-binding protein-2 (Fig. 6b) were tested as positive markers of undifferentiated 
a

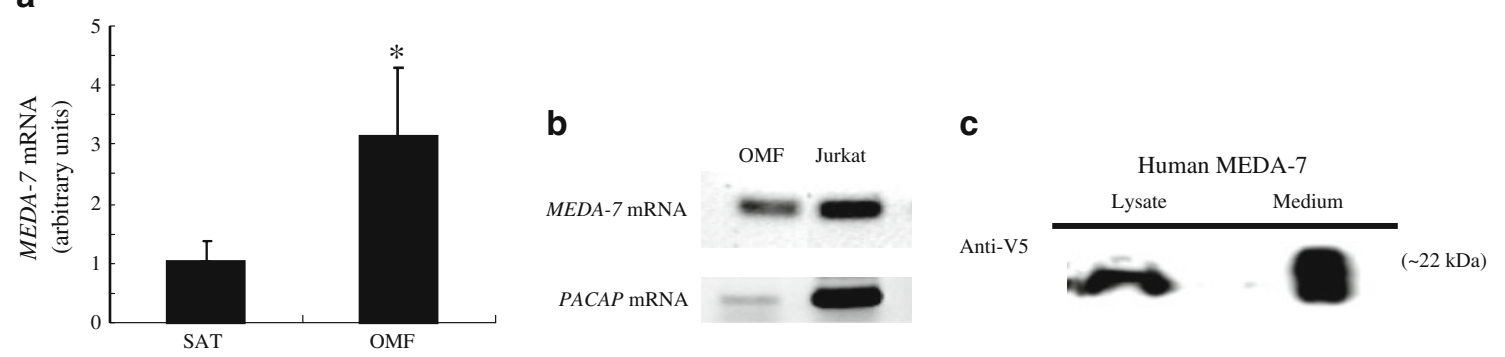

Fig. 4 Characterisation of $M E D A-7$ in human adipose tissue. a MEDA-7 expression assessed by quantitative PCR in SAT and omental fat depots (OMF) of obese patients; $n=4 ; * p<0.05$. b Relative expression of MEDA-7 and its shorter form (PACAP, see text) in omental fat depot. $M E D A-7$ is predominant in omental fat.

and fully differentiated states on day 8 . Insulin-dependent glucose uptake was reduced after incubation of cells with recombinant MEDA-7 protein ( 2 and $5 \mathrm{nmol} / \mathrm{l}$ ), while basal glucose uptake remained unchanged (Fig. 6c). This was associated with an increase of suppressor of cytokine signalling (SOCS)-3 (Fig. 6d) and Mcp-1 (also known as Ccl2) mRNA (Fig. 6e) and reduction of Glut4 (also known as Slc2a4) at mRNA (Fig. 6f) and protein levels (Fig. 6g). As a control for the fractioning process, $\beta$-actin was not detected from membrane fraction (Fig. $6 \mathrm{~g}$ ) and insulin receptor- $\beta$ was barely detected in the cytosol fraction (Fig. 6h). GLUT4 protein was downregulated in total lysate (Fig. 6i) and membrane fraction (Fig. 6j) upon MEDA-7 treatment after insulin stimulation. Level of the key downstream insulin signalling pathway protein, phospho AKT, was also downregulated (Fig. 6k). However, phospho insulin receptor- $\beta$ and phospho IRS-1 were unaltered (data not shown). Therefore, MEDA-7 contributed to the chronic inflammatory state of adipocytes and blunted insulindependent glucose uptake in adipocytes.

\section{Discussion}

Insulin resistance in obesity is closely related to the presence of inflammatory cells in adipose tissue, in particular a population of macrophages, which cause lowgrade chronic inflammation and release various cytokines $[14,16]$. Within the visceral area in female mice with hormonal imbalance, we previously showed that the inflammatory nature of MAT is different from that of the neighbouring perigonadal fat [22]. With the object of identifying the genes responsible for different effects, our study reports the cloning and characterisation of a novel gene, Meda-7/MEDA-7, in mice and humans. The changing dynamics of Meda-7 expression in MAT in For-knockout mutants as they aged and approached a prediabetic state attracted our attention. In For-knockout mutants, Meda-7
Jurkat cells used as positive control in PCR show higher PACAP expression. c Human MEDA-7 ORF cloned in pIRES2V5-eGFP vector and transfected into HEK-293 cells shows efficient secretion of the processed protein. Western blot was performed using V5 antibody

was first downregulated at 5 months, when mice are in an early obese state with normal glucose tolerance. However, its upregulation at 9 months, in a prediabetic state, implied that Meda-7 plays a role in advanced obesity and development of insulin resistance. As a secreted protein, MEDA-7 is produced predominantly in adipose tissue SVC, which is composed of several cell types [11]. Its abundance in the macrophage M1 phenotype (Fig. 2g) supports an association with the chronic inflammatory state of adipose tissue and glucose intolerance in For-knockout mutants [22]. LPS-activated macrophages, which have been shown to increase proinflammatory cytokines [25] including Tnf $\alpha, I l-1 \beta$ and $I l-12$, also promote Meda-7 expression. This also supported the proinflammatory phenotype of MEDA-7. MEDA-7 secreted protein was able to decrease insulin-dependent glucose uptake in 3T3-L1 cells. This is associated with downregulation of GLUT4 and pAKTactivity, and upregulation of $M c p-1$ and Socs-3, leading to blunting of insulin sensitivity in adipocytes [42, 43]. Therefore, Meda-7 upregulation could contribute to the progression of insulin resistance in adipose tissue. In agreement with this, our previous study showed upregulation of other proinflammatory genes, e.g. Tnf $\alpha$ (also known as Tnf) and Mcp-1, in MAT of 9-month-old, but not in that of 5-month-old obese mutants [22]. Other studies have also confirmed that in obesity, overproduction of macrophage-derived cytokines causes insulin resistance by downregulating Glut4 [44].

MAT in rodents resembles human omental fat. Both are major abdominal fat depots showing a causal relationship between visceral obesity and insulin resistance. MAT is a better insulin sensitivity marker than other abdominal fat depots [13]. Meda-7 dysregulation in mutant MAT is greater than in PAT, which is also consistent with our previous findings of prominent alterations of anti/pro insulin resistance adipokines, including adiponectin, Tnf $\alpha$ and $M c p-1$ in MAT [22]. MEDA-7 abundance in obese humans also varies according to adipose tissue location, being higher in omental fat than SAT (Fig. 4a). Thus, based 

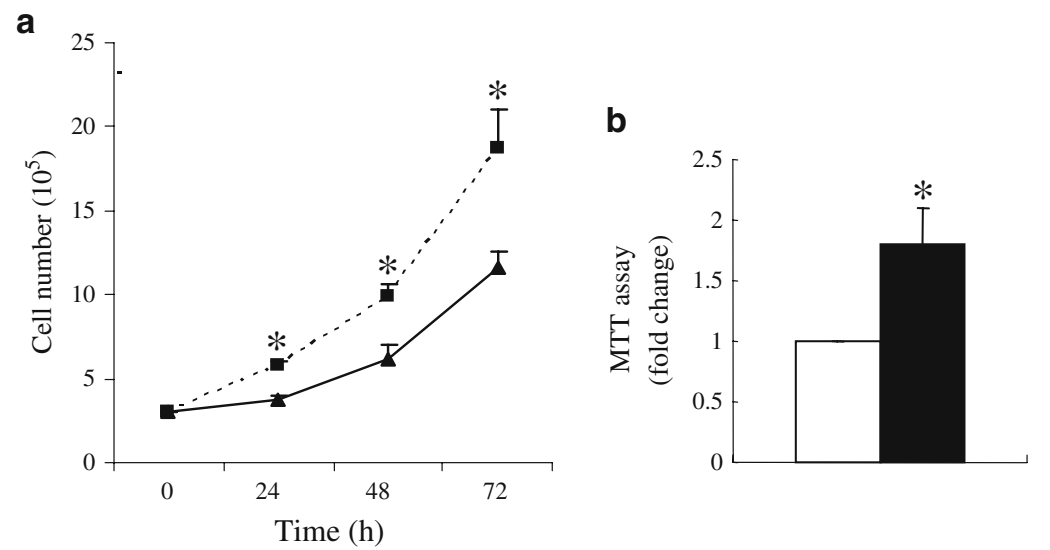

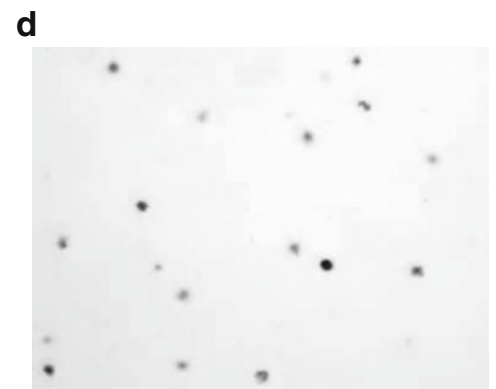

UCI-107 vector

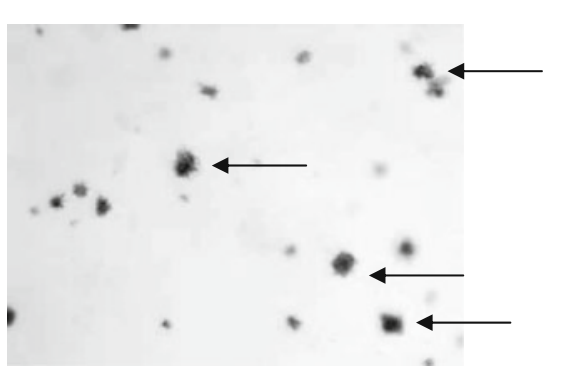

UCI-107 human MEDA-7
C

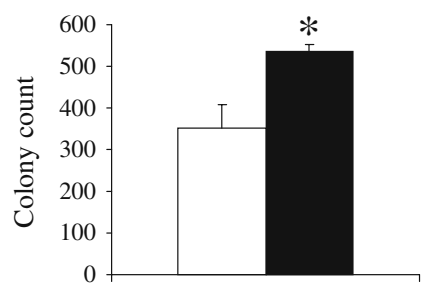

e

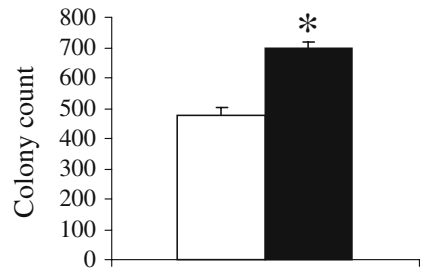

f

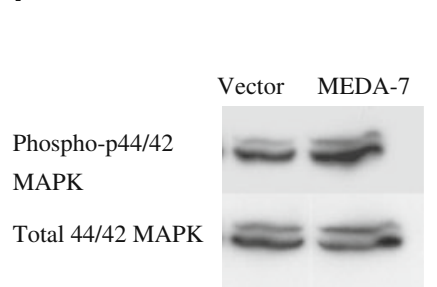

g

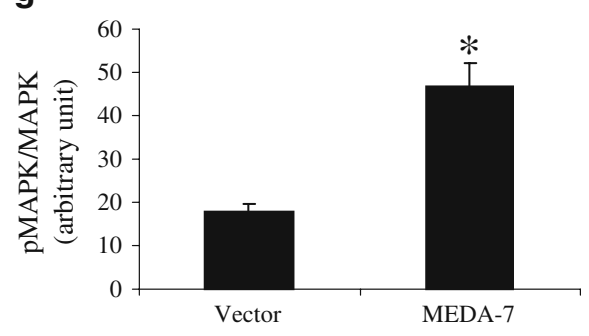

Fig. 5 MEDA-7 increases cell proliferation. a Cells $\left(3 \times 10^{5}\right)$ were plated in each dish and cell number counted at indicated times. Trypan blue staining was used to indicate dead cells. $n=4, * p<0.05$. Triangles, HEK-293 vector; squares, HEK-293 MEDA-7. b Cells were plated in 96 -well plates $\left(10^{4} /\right.$ well $)$ for $48 \mathrm{~h}$ and processed by MTT assay; absorbance was observed at $570 \mathrm{~nm} . n=4,{ }^{*} p<0.05$. White, HEK-293 vector; black, HEK-293 MEDA-7. c Colony formation in HEK-293 human MEDA-7 cells (black bars) vs HEK293 vector (white bars). $n=3, * p<0.05$. d Images of colony formation in UCI-107 ovarian cancer cells transfected with human MEDA-7

Table 1 Cell cycle analysis in HEK293-MEDA-7 cells

\begin{tabular}{llll}
\hline Variable & G1 & $\mathrm{S}$ & $\mathrm{G} 2$ \\
\hline HEK293-vector & $57.5 \pm 2.0$ & $30.13 \pm 4.0$ & $12.37 \pm 2.4$ \\
HEK293-MEDA-7 & $54.1 \pm 2.6$ & $36.76 \pm 4.4^{*}$ & $9.2 \pm 2.0$ \\
\hline
\end{tabular}

Values are mean \pm SEM, $n=3$

$* p<0.05$
ORF, with (e) quantification. Cells were seeded in triplicate at a density of $1 \times 10^{5}$ per $3.5 \mathrm{~cm}$ dishes in $0.3 \%$ (wt/vol.) soft agar medium. After 2 weeks growth, the cells were stained with crystal violet $(0.005 \%$, wt $/ \mathrm{vol}$.). The number of colonies were counted and expressed per field of view; $n=3,{ }^{*} p<0.05$. White, UCI-107 vector; black, UCI-107 MEDA-7. f p42/44 MAPK activity in HEK-293 human $M E D A-7$. Representative western blots probed with phosphop44/42 MAPK antibody and with 44/42 MAPK antibody are shown. Activity of p44/42 MAPK was normalised to total 44/42 MAPK. g Quantification of blots; $n=3,{ }^{*} p<0.05$

on findings in mice and obese humans, we attribute significance to the high abundance of $M E D A-7$ in deep VAT.

Reversal of Meda-7 downregulation in For-knockout mouse adipose tissue by oestrogen at an early age but not later confirms its role as an important age-dependent regulator (Fig. 3). As transcription factor prediction by multiTF program (http://dcode.org) indicated that mouse and human $M E D A-7$ promoter regions contain an oestrogen receptor binding site, we suggest that part of the regulation occurs at the transcriptional level. Failure of oestrogen to 
a

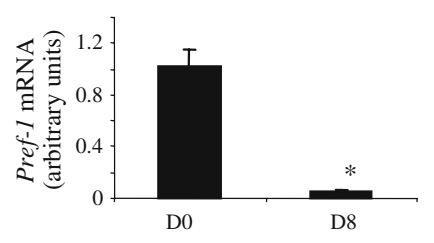

d

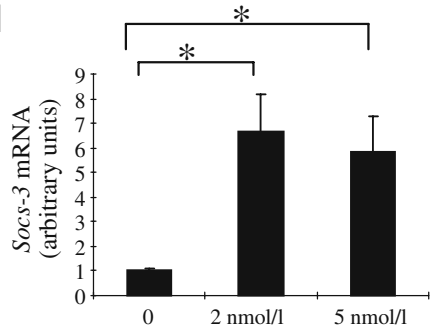

g

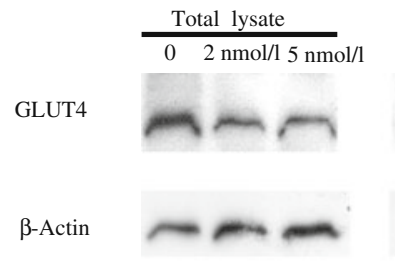

h

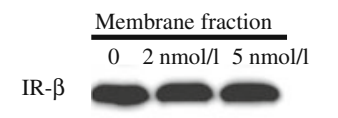

i

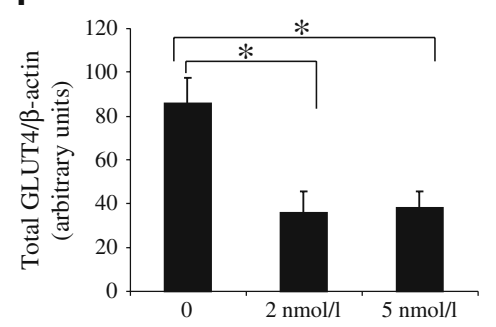

b

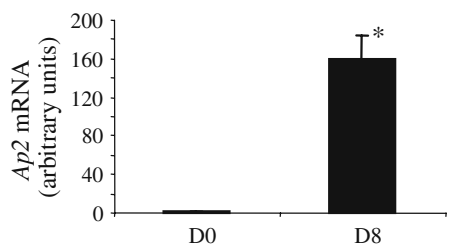

e

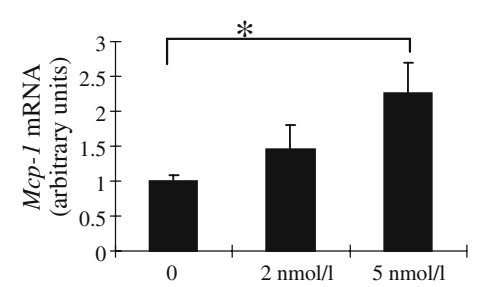

C

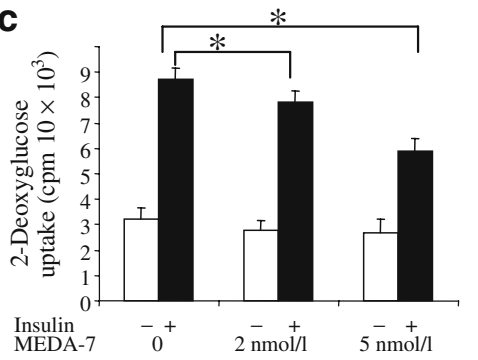

$\mathbf{f}$

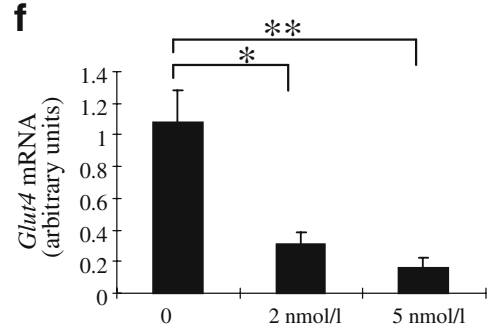

$\frac{\text { Membrane fraction }}{02 \mathrm{nmol} / 15 \mathrm{nmol} / 1}$
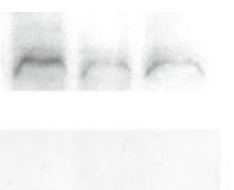

$\frac{\text { Cytosol fraction }}{0 \quad 2 \mathrm{nmol} / 15 \mathrm{nmol} / 1}$

$2 \mathrm{nmol} / 5 \mathrm{nmol} / 1$

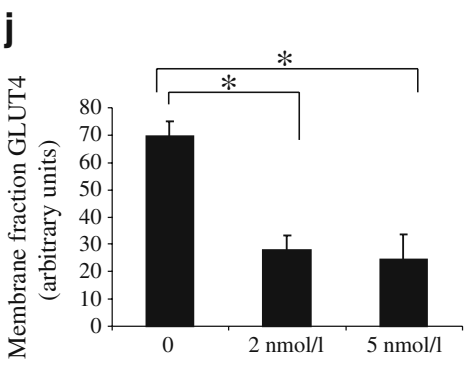

k

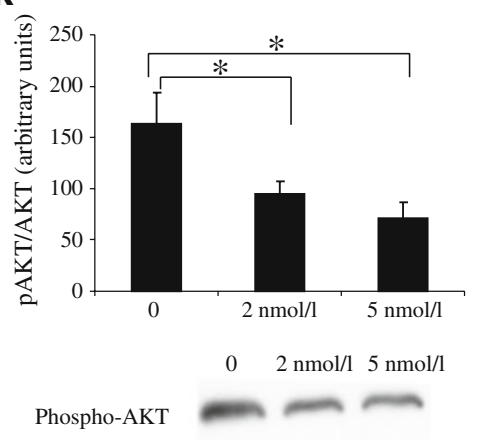

Total AKT

quantitative PCR; $n=6$. $\mathbf{g}$ GLUT4 protein level was measured in plasma membrane and total cell lysate. Representative western blots are shown. $\beta$-Actin was not detected from membrane fraction. $\mathbf{h}$ Insulin receptor (IR)- $\beta$ was barely detected in the cytosol fraction, confirming the fractionation process. Band density was quantified after probing with GLUT4 antibody in (i) total lysate and (j) membrane fraction; $n=4$. k Phospho AKT (pAKT) activity was measured in total cell lysate. Representative western blots probed with pAKT and AKT antibodies are shown. pAKT was normalised to total AKT and quantified; $n=4 .{ }^{*} p<0.05$ and ${ }^{* *} p<0.01$

mice after prolonged oestrogen deficiency [22]. Our results are supported by other studies in animal models or human 
participants, which indicate that timing is critical to deriving benefits from hormone replacement. Specifically, beneficial effects of oestrogen replacement on risk of coronary events and progression of atherosclerosis are evident when therapy is initiated early in the postmenopausal period, but these are lost in participants who have pre-existing coronary artery atherosclerosis and are several years beyond the onset of menopause [45, 46].

There appears to be a single transcript of the Meda-7 gene, as our cloning showed a single band that was identified as Meda-7 cDNA in mice. However, human $M E D A-7$ has one additional isoform that has been previously cloned and characterised as PACAP [40]. This PACAP protein, binding to caspase-2 and caspase-9, induced apoptosis in HEK-293 cells and rat-1 fibroblasts. A frame shift caused by alternative splicing produced this transcript.
Its low expression in obese human adipose tissue (Fig. 4b) compared with the levels of MEDA-7 mRNA and the corresponding protein suggests that PACAP protein is unlikely to be of biological significance in this setting. For several reasons, we point out that using the PACAP acronym for MEDA-7 variant (EST AA769445) is erroneous and misleading, as another, better characterised molecule, the pituitary adenylate cyclase activating peptide (the original $P A C A P$ and redesignated $A D C Y A P 1$ ), had been identified much earlier and extensively investigated for its neuroendocrine function and regulation, including a role in energy metabolism [47]. As indicated by its effects on HEK-293 cells, neither mouse nor human MEDA-7 protein is deleterious for cell survival or growth. On the contrary, both have significant cell-stimulating activity via activation of MAPK (Fig. 5g). This conclusion is also supported by

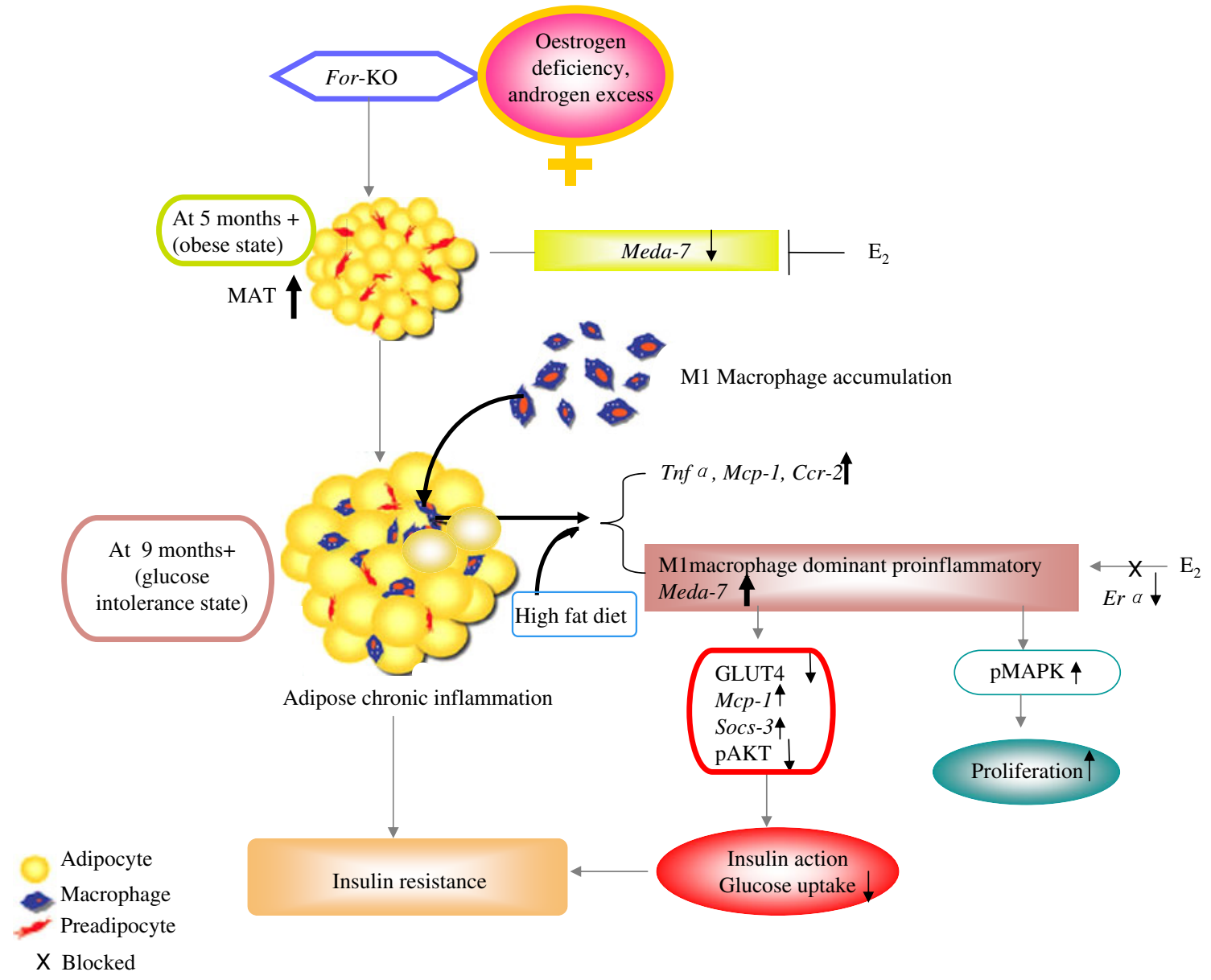

Fig. 7 Mechanisms linking visceral obesity and insulin resistance in For-knockout (For-KO) female mice. Chronic hormonal imbalance consisting of combined oestrogen deficiency and androgen excess causes visceral obesity and macrophage activation. As the inflammatory state intensifies, Meda-7 among other factors is upregulated by 9 months to cause cellular expansion via robust activation of pMAPK44/42 and blunting of insulin response in adipocytes by decrease of GLUT4, increase of Mcp-1 and Socs-3 abundance, and reduction of pAKT activity. Meda-7 downregulation in MAT of For knockouts can be reversed by oestrogen at 5 months, but the effect is lost at 9 months, by which time oestrogen receptor (ER)- $\alpha$ abundance in adipose tissue is also diminished. As shown previously [21, 22], For-knockout females acquire insulin resistance and the metabolic syndrome characteristics by 12 months. HFD causes pronounced upregulation of Meda-7 expression in the adipose tissue, exacerbating the inflammatory state. CCR2, chemokine (C-C motif) receptor $2 . \mathrm{E}_{2}$, oestradiol-17 $\beta$ 
enhanced anchorage-independent growth in HEK-293 and UCI-107 ovarian cancer cells.

The gene corresponding to MEDA-7 is also known as MGC 29506, which is apparently downregulated in intestinal-type gastric cancer [41]. The gene's functional significance in this context is unknown. Our study is the first to clone Meda-7 ORF from mouse and human adipose tissue. As our findings indicate that Meda-7 is also expressed in other metabolically active organs such as the heart, muscle, kidney and pancreas (Fig. 2a) in mice, the novel protein may have additional roles in different targets. Therefore cellular context-dependent functions of MEDA-7 are possible. Thus when we had completed our MEDA-7 studies in adipose tissue and obesity and were in the process of preparing this manuscript, two papers reporting a similar transcript and identifying an endoplasmic resident protein named $\mathrm{pERp} 1$ in the immune system came to our attention. This entity has been attributed a chaperone function during immunoglobulin assembly [48, 49].

In conclusion, our studies identified a novel secreted protein called MEDA-7, which is produced in mouse and human adipose tissue and is regulated by oestrogen in a fat depot- and age-dependent manner. MEDA-7, as a new proinflammatory cytokine, provides an additional link between obesity and onset of insulin resistance. We visualise a scenario (Fig. 7) in which MEDA-7 upregulation occurs at later ages in For-knockout female mice with hormonal imbalances associated with chronic inflammatory states, and progression to local and systemic insulin resistance in mutants. MEDA-7 predominantly expressed in SVC and localised in proinflammatory M1 macrophages has a direct effect on glucose uptake triggered by insulin in adipocytes. MEDA-7 also promotes cell growth in other cell types such as ovarian cancer. Thus MEDA-7 is a novel hormonally regulated adipokine/cytokine implicated in causing chronic inflammation, controlling cellular expansion and contributing to development of insulin resistance.

\begin{abstract}
Acknowledgements A preliminary report of this study was presented at the NASSO meeting in Washington DC in October 2009. This work was supported in part by grants from the JNJ (New Brunswick, NJ, USA) Focused Giving Program and Canadian Institutes of Health Research. We thank our colleagues P. Leclerc of the Hotel-Dieu hospital, and R. Rabassa-Lhoret and M. Faraj at the IRCM for their help in securing fat tissue samples from patients. We are also grateful to J. P. Aravindakshan for help in the initial microarray studies.

$\mathrm{HZ}$ designed the study, performed experiments, researched data and wrote the manuscript. XC researched and analysed data. MRS designed the study, researched data, contributed to discussions and reviewed and edited the manuscript. All authors have approved this final version.
\end{abstract}

Duality of interest The authors declare that there is no duality of interest associated with this manuscript.

\section{References}

1. Carr MC (2003) The emergence of the metabolic syndrome with menopause. J Clin Endocrinol Metab 88:2404-2411

2. Gambineri A, Pelusi C, Vicennati V, Pagotto U, Pasquali R (2002) Obesity and the polycystic ovary syndrome. Int J Obes 26:883896

3. Knopp RH (2002) Risk factors for coronary artery disease in women. Am J Cardiol 89:28-34

4. Cussons AJ, Stuckey BGA, Watts GF (2006) Cardiovascular disease in the polycystic ovary syndrome: new insights and perspectives. Atherosclerosis 185:227-239

5. Szmuilowicz ED, Stuenkel CA, Seely EW (2009) Influence of menopause on diabetes and diabetes risk. Nat Rev Endocrinol 5:553-558

6. Munoz J, Derstine A, Gower BA (2002) Fat distribution and insulin sensitivity in postmenopausal women: influence of hormone replacement. Obesity 10:424-431

7. Kanis JA, Delmas P, Burckhardt P, Cooper C, Torgerson D (1997) Guidelines for diagnosis and management of osteoporosis. Osteoporos Int 7:390-406

8. Rosano GMC, Vitale C, Fini M (2009) Cardiovascular aspects of menopausal hormone replacement therapy. Climacteric 12:41-46

9. Rossouw JE, Prentice RL, Manson JE et al (2007) Postmenopausal hormone therapy and risk of cardiovascular disease by age and years since menopause. JAMA 297:1465-1477

10. Arner P (2001) Regional differences in protein production by human adipose tissue. Biochem Soc Trans 29:72-75

11. Schaffler A, Scholmerich J, Buchler C (2005) Mechanisms of disease: adipocytokines and visceral adipose tissue-emerging role in intestinal and mesenteric diseases. Nat Clin Pract Gastroenterol Hepatol 2:103-111

12. Bjorntorp P (1990) "Portal" adipose tissue as a generator of risk factors for cardiovascular disease and diabetes. Arterioscler Thromb Vasc Biol 10:493-496

13. Catalano KJ, Stefanovski D, Bergman RN (2010) Critical role of the mesenteric depot vs other intra-abdominal adipose depots in the development of insulin resistance in young rats. Diabetes 59:1416-1423

14. Harman-Boehm I, Bluher M, Redel H et al (2007) Macrophage infiltration into omental vs subcutaneous fat across different populations: effect of regional adiposity and the comorbidities of obesity. J Clin Endocrinol Metab 92:2240-2247

15. Weisberg SP, McCann D, Desai M, Rosenbaum M, Leibel RL, Ferrante AW (2003) Obesity is associated with macrophage accumulation in adipose tissue. J Clin Invest 112:1796-1808

16. Wentworth JM, Naselli G, Brown WA et al (2010) Pro-

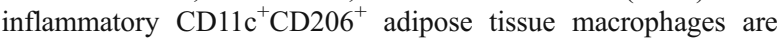
associated with insulin resistance in human obesity. Diabetes 59:1648-1656

17. Greenberg AS, Obin MS (2006) Obesity and the role of adipose tissue in inflammation and metabolism. Am J Clin Nutr 83:461S$465 \mathrm{~S}$

18. Maeda K, Okubo K, Shimomura I, Mizuno K, Matsuzawa Y, Matsubara K (1997) Analysis of an expression profile of genes in the human adipose tissue. Gene 190:227-235

19. Danilovich N, Babu PS, Xing W, Gerdes M, Krishnamurthy H, Sairam MR (2000) Estrogen deficiency, obesity, and skeletal abnormalities in follicle-stimulating hormone receptor knockout (FORKO) female mice. Endocrinology 141:4295-4308

20. Dierich A, Sairam MR, Monaco L et al (1998) Impairing folliclestimulating hormone (FSH) signaling in vivo: targeted disruption of the FSH receptor leads to aberrant gametogenesis and hormonal imbalance. Proc Natl Acad Sci USA 95:13612-13617 
21. Sairam MR, Wang M, Danilovich N, Javeshghani D, Maysinger D (2006) Early obesity and age-related mimicry of metabolic syndrome in female mice with sex hormonal imbalances. Obesity $14: 1142-1154$

22. Zhang H, Chen X, Aravindakshan J, Sairam MR (2007) Changes in adiponectin and inflammatory genes in response to hormonal imbalances in female mice and exacerbation of depot selective visceral adiposity by high-fat diet: implications for insulin resistance. Endocrinology 148:5667-5679

23. Aravindakshan J, Chen XL, Sairam MR (2010) Chronology and complexities of ovarian tumorigenesis in FORKO mice: agedependent gene alterations and progressive dysregulation of major histocompatibility complex (MHC) class I and II profiles. Mol Cell Endocrinol 329:37-46

24. Nishimura S, Manabe I, Nagasaki M et al (2009) $\mathrm{CD}^{+}$effector $\mathrm{T}$ cells contribute to macrophage recruitment and adipose tissue inflammation in obesity. Nat Med 15:914-920

25. Tripathi S, Bruch D, Kittur D (2008) Ginger extract inhibits LPS induced macrophage activation and function. BMC Complement Altern Med 8:1

26. Medina EA, Afsari RR, Ravid T, Castillo SS, Erickson KL, Goldkorn T (2005) Tumor necrosis factor- $\alpha$ decreases Akt protein levels in 3T3-L1 adipocytes via the caspase-dependent ubiquitination of Akt. Endocrinology 146:2726-2735

27. Choi SS, Cha BY, Iida K et al (2011) Artepillin C, as a PPAR [gamma] ligand, enhances adipocyte differentiation and glucose uptake in 3T3-L1 cells. Biochem Pharmacol 81:925-933

28. Svenson KL, von Smith R, Magnani PA et al (2007) Multiple trait measurements in 43 inbred mouse strains capture the phenotypic diversity characteristic of human populations. J Appl Physiol 102:2369-2378

29. Olson TS, Ley K (2002) Chemokines and chemokine receptors in leukocyte trafficking. Am J Physiol Regul Integr Comp Physiol 283:R7-R28

30. Walter MR, Cook WJ, Zhao BG et al (1992) Crystal structure of recombinant human interleukin-4. J Biol Chem 267:20371-20376

31. Riollet C, Mutuel D, Duonor-Cerutti M, Rainard P (2006) Determination and characterization of bovine interleukin-17 cDNA. J Interferon Cytokine Res 26:141-149

32. Huang N, Chen H, Sun Z (2005) CTKPred: an SVM-based method for the prediction and classification of the cytokine superfamily. Protein Eng Des Sel 18:365-368

33. Bradley JR, Pober JS (2001) Tumor necrosis factor receptorassociated factors (TRAFs). Oncogene 20:6482-6491

34. Takeuchi M, Rothe M, Goeddel DV (1996) Anatomy of TRAF2. Distinct domains for nuclear factor-kappaB activation and association with tumor necrosis factor signaling proteins. J Biol Chem 271:19935-19942
35. Ghilardi N, Ziegler S, Wiestner A, Stoffel R, Heim MH, Skoda RC (1996) Defective STAT signaling by the leptin receptor in diabetic mice. Proc Natl Acad Sci USA 93:6231-6235

36. Darnell JE (1996) Reflections on STAT3, STAT5, and STAT6 as fat STATs. Proc Natl Acad Sci USA 93:6221-6224

37. Blank U, Launay P, Benhamou M, Monteiro RC (2009) Inhibitory ITAMs as novel regulators of immunity. Immunol Rev 232:59-71

38. Lumeng CN, Bodzin JL, Saltiel AR (2007) Obesity induces a phenotypic switch in adipose tissue macrophage polarization. J Clin Invest 117:175-184

39. Fujihara M, Muroi M, Ki T, Suzuki T, Azuma H, Ikeda H (2003) Molecular mechanisms of macrophage activation and deactivation by lipopolysaccharide: roles of the receptor complex. Pharmacol Ther 100:171-194

40. Bonfoco E, Li E, Kolbinger F, Cooper NR (2001) Characterization of a novel proapoptotic caspase-2- and caspase-9-binding protein. J Biol Chem 276:29242-29250

41. Katoh M, Katoh M (2003) MGC29506 gene, frequently downregulated in intestinal-type gastric cancer, encodes secreted-type protein with conserved cysteine residues. Int J Oncol 23:235-241

42. Shoelson SE, Lee J, Goldfine AB (2006) Inflammation and insulin resistance. J Clin Invest 116:1793-1801

43. Ueki K, Kondo T, Kahn CR (2004) Suppressor of cytokine signaling 1 (SOCS-1) and SOCS-3 cause insulin resistance through inhibition of tyrosine phosphorylation of insulin receptor substrate proteins by discrete mechanisms. Mol Cell Biol 24:5434-5446

44. Armoni M, Harel C, Karnieli E (2007) Transcriptional regulation of the GLUT4 gene: from PPAR-[gamma] and FOXO1 to FFA and inflammation. Trends Endocrinol Metab 18:100-107

45. Manson JE, Bassuk SS (2007) Invited commentary: hormone therapy and risk of coronary heart disease why renew the focus on the early years of menopause? Am J Epidemiol 166:511-517

46. Cann JA, Register TC, Adams MR, St. Clair RW, Espeland MA, Williams JK (2008) Timing of estrogen replacement influences atherosclerosis progression and plaque leukocyte populations in $\mathrm{ApoE}^{-/-}$mice. Atherosclerosis 201:43-52

47. Rawlings S, Hezaren M (1996) Pituitary adenylate cyclase-activating polypeptide (PACAP) and PACAP/vasoactive intestinal polypeptide receptors: actions on the anterior pituitary gland. Endocr Rev 17:4-29

48. Shimizu Y, Meunier L, Hendershot LM (2009) pERp1 is significantly up-regulated during plasma cell differentiation and contributes to the oxidative folding of immunoglobulin. Proc Natl Acad Sci USA 106:17013-17018

49. van Anken E, Pena F, Hafkemeijer N et al (2009) Efficient IgM assembly and secretion require the plasma cell induced endoplasmic reticulum protein pERp1. Proc Natl Acad Sci USA 106:17019-17024 